ORIGINAL ARTICLE

\title{
Characteristics of drowning by different age groups
}

\section{Quan, P Cummings}

Injury Prevention 2003;9:163-168

Context: While it is known that the risk of unintentional drowning varies with age, the manner in which drowning episode characteristics vary by age has not been well described. Such information might be useful for prevention.

Objective: To describe characteristics of drowning by age group.

Design: Retrospective review of the characteristics of drowning victims and their drowning incidents obtained from death certificates, medical examiner, pre-hospital, emergency department, and hospital records.

Setting: Three counties in Western Washington state.

Subjects: Residents who died $(n=709)$ of unintentional drowning within the study region during 1980 through 1995.

Outcomes: Age specific counts, proportions, and rates per million person years were estimated for and compared among six age groups.

Results: Rates varied by age group: 0-4 (30.5), 5-14 (1 1.6), 15-19 (29.9), 20-34 (21.5), 35-64 (12.5), and 65 years or older (21.2). Among those 0-4 years, the proportions that drowned in pools, bathtubs, and open water were nearly equal. But from age 5-64 years, over $69 \%$ of deaths were in

See end of article for authors' affiliations

Correspondence to: Dr Linda Quan, Emergency Services CH04, Children's Hospital and Regional Medical Center, 4800 Sand Point Way NE, Seattle, WA 90105, USA: Linda.quan@ seattlechildrens.org open water. Among those 65 years and older, the deaths were almost evenly divided between bathtub and open water; bathtub drowning rates were highest in this age group, 10.9. Pre-drowning activities were divided into boating, swimming, car passenger, bathing, and fell in while doing something else. Most $(64 / 89,76 \%)$ victims aged 0-4 years drowned while bathing or after falling in. Among those 15-19 years, most occurred while swimming (24/79, 34\%) or boating $(22 / 79,31 \%)$. The drowning event was least often witnessed among those $0-4$ years (10/36, 28\%), and most often witnessed $(44 / 58,76 \%)$ among those 15-19 years. Medical care (pre-hospital, emergency department, or hospital) was most often involved in drownings of those $0-4$ years $(70 / 89,79 \%)$ and least among those over 65 years $(11 / 86,13 \%)$.

Conclusion: The characteristics of drowning episodes vary greatly by age. Different prevention strategies may be needed for different age groups.

$\mathrm{D}$ rowning rates are known to vary greatly with age. ${ }^{1-9}$ Variation in the bodies of water in which children of different ages drown has been described in several regional and national studies. ${ }^{6}{ }^{10} 11$ Variation in the bodies of water in which children of different ages drown has been described using a US national dataset of death certificates. ${ }^{2}$ However, little is known about the circumstances of drowning as they relate to the victim's age. This is because death certificate files, the data source for most studies, have limited information about circumstances and do not allow a clear depiction of how and why drownings occur. Information on drowning circumstances that would be useful include what the victim was doing before the drowning, the presence of contributing medical or psychiatric conditions, and whether the drowning was witnessed.

We sought to describe variation in drowning circumstances with age. We compared the characteristics of the victim, the drowning event, and use of medical resources by age group. Recognition of circumstances unique to specific age groups might allow more specific approaches to drowning prevention.

\section{METHODS}

We collected data regarding drowning episodes in King, Snohomish, and Pierce Counties, Washington, from l January 1980, through 31 December 1995. These counties had 2559164 residents in $1990 . .^{12}$ Information was abstracted from the investigative and autopsy reports of the medical examiner's office in each county, hospital records of patients with drowning (International Classification of Diseases, 9th revision, clinical modification (ICD9-CM) code $994.1^{13}$ ) in the discharge registries of all 26 acute care hospitals, and incident reports of victims with a mechanism of drowning in the four major emergency medical services agencies in the region.

Case finding was supplemented by using the computerized files of Washington State death certificates for all study years, and computerized files of state civilian hospital discharges with the diagnosis of drowning (ICD9 code 994.1) from 1987 through 1996.

\section{Variable definitions}

Age in years was categorized as 0-4, 5-14, 15-19, 20-34, 35-64, and 65 and older. All activity before drowning was grouped into five categories: (1) boating, including fishing from a boat; (2) swimming or diving; (3) occupant of a car that went into the water; (4) fell into water from a dock or from shore or while wading; (5) bathing. Seasons were categorized as cold (November through February), mild (March, April, September, October), and warm (May through August). Body of water was categorized as (1) swimming pool; (2) bathtub; (3) open water, an outside body of water other than a swimming pool, such as a lake, river, or pond. Rural and urban designations were based on census designations for 1990. Information sought included a history of prior seizures, diabetes, heart disease, and psychiatric disorders. Categorization of intent was based on the medical examiners' determination. Drownings of undetermined intent $(n=90)$ were not included in the analyses. 
Table 1 Number (\%) of submersion deaths in three Washington State counties, 1980-95, by category of age; proportions by characteristics of the victim or the drowning event*

\begin{tabular}{|c|c|c|c|c|c|c|c|}
\hline \multirow[b]{2}{*}{ Characteristics } & \multicolumn{6}{|c|}{ Age group (years) } & \multirow[b]{2}{*}{ All ages } \\
\hline & $0-4$ & $5-14$ & $15-19$ & 20-34 & $35-64$ & $\geqslant 65$ & \\
\hline All & $89(100)$ & $62(100)$ & $79(100)$ & $225(100)$ & $168(100)$ & $86(100)$ & 709 (100) \\
\hline \multicolumn{8}{|l|}{ Sex } \\
\hline Male & 62 (70) & 52 (84) & $67(85)$ & 197 (88) & $131(78)$ & $47(55)$ & $556(78)$ \\
\hline Female & 27 (30) & $10(16)$ & $12(15)$ & $28(12)$ & 37 (22) & $39(45)$ & $153(22)$ \\
\hline \multicolumn{8}{|l|}{ Race } \\
\hline White & 75 (88) & 44 (72) & 64 (82) & $179(80)$ & 149 (89) & 76 (89) & $587(84)$ \\
\hline Black & $8(9)$ & $13(21)$ & $5(6)$ & $23(10)$ & $14(8)$ & $2(2)$ & $65(9)$ \\
\hline Hispanic & 0 & 0 & 1 (1) & $6(3)$ & $1(1)$ & $1(1)$ & 9 (1) \\
\hline Asian & $1(1)$ & $4(7)$ & $8(10)$ & 7 (3) & 0 & $6(7)$ & $26(4)$ \\
\hline Native American & $1(1)$ & 0 & 0 & $9(4)$ & $4(2)$ & 0 & $14(2)$ \\
\hline \multicolumn{8}{|l|}{ Seasont } \\
\hline Cold & $16(18)$ & $9(15)$ & $14(18)$ & $52(23)$ & $47(28)$ & $24(28)$ & $162(23)$ \\
\hline Mild & $23(26)$ & $14(23)$ & 14 (18) & $68(30)$ & 52 (31) & $23(27)$ & $194(27)$ \\
\hline Warm & $50(56)$ & $39(63)$ & $51(65)$ & 105 (47) & 69 (41) & $38(44)$ & $352(50)$ \\
\hline Event witnessedt & 10 (12) & $16(34)$ & $44(76)$ & 113 (70) & 53 (50) & $9(29)$ & $245(50)$ \\
\hline \multicolumn{8}{|l|}{ Body of water } \\
\hline Pool & $32(36)$ & 15 (24) & $2(3)$ & $9(4)$ & $14(8)$ & $8(9)$ & $80(11)$ \\
\hline Bathtub & $26(29)$ & $4(6)$ & $2(3)$ & $16(7)$ & 26 (15) & 44 (51) & 118 (17) \\
\hline Outside & 31 (35) & $43(69)$ & 75 (95) & 200 (89) & $128(76)$ & $34(40)$ & $511(72)$ \\
\hline Rural location & 30 (35) & 35 (62) & 57 (77) & 139 (64) & 94 (59) & $30(36)$ & $385(57)$ \\
\hline \multicolumn{8}{|l|}{ Activity } \\
\hline Boating & 0 & $7(13)$ & $22(31)$ & $54(28)$ & 39 (27) & $5(6)$ & $127(20)$ \\
\hline Swimming & $1(1)$ & $20(37)$ & 24 (34) & 49 (25) & 14 (10) & $6(8)$ & $114(18)$ \\
\hline In car & 0 & 1 (2) & 11 (15) & $28(14)$ & $18(12)$ & $2(3)$ & $60(10)$ \\
\hline Fell in & 64 (74) & 21 (39) & 12 (17) & 48 (25) & $41(28)$ & 21 (27) & 207 (33) \\
\hline Bathing & 21 (24) & 5 (9) & $2(3)$ & $17(9)$ & $33(23)$ & 45 (57) & 123 (19) \\
\hline Was in a boat & 1 (1) & 7 (12) & 21 (29) & 70 (33) & 53 (33) & 12 (14) & $164(24)$ \\
\hline Seizure history & $4(5)$ & $8(15)$ & 7 (11) & $18(9)$ & 24 (16) & $3(4)$ & 64 (10) \\
\hline Diabetes & 0 & 0 & $1(2)$ & 2 (1) & $4(3)$ & $4(6)$ & $11(2)$ \\
\hline Heart disease & $2(2)$ & 0 & $1(2)$ & $2(1)$ & $40(30)$ & $63(84)$ & 108 (18) \\
\hline Psychiatric disorder & 0 & $1(2)$ & 0 & $8(5)$ & $12(11)$ & 7 (14) & $28(5)$ \\
\hline Alcohol used & 0 & 0 & $10(13)$ & 75 (33) & $58(35)$ & 11 (13) & $154(22)$ \\
\hline Bystander resuscitation & 64 (84) & $27(60)$ & $15(21)$ & 40 (19) & $35(23)$ & 14 (18) & $195(31)$ \\
\hline Used pre-hospital care & 77 (87) & $41(68)$ & $23(30)$ & 75 (33) & 63 (39) & $25(30)$ & $304(44)$ \\
\hline Used emergency department care & 68 (79) & $34(61)$ & $16(22)$ & 44 (20) & $29(18)$ & $8(10)$ & 199 (30) \\
\hline Used hospital care & $35(40)$ & $16(27)$ & $6(8)$ & $19(9)$ & $16(10)$ & $8(9)$ & $100(15)$ \\
\hline
\end{tabular}

*Some data missing for most row categories. Categories with more than $10 \%$ missing data were: event witnessed $(31 \%)$, activity (11\%), diabetes (16\%), heart disease $(15 \%)$, psychiatric disorder $(24 \%)$, bystander resuscitation $(11 \%)$.

tCold season is November, December, January, February. Mild season is March, April, September, October. Warm season is May, June, July, August.

\section{Statistical analysis}

Rates were calculated per million person years. To estimate population based rates, we included only deaths of area residents who drowned in the three county study region. (During the study period, $32.5 \%$ of the drowned residents drowned outside of the study region, the proportion was lowest for children 0-4 years ( $11.9 \%$ ) and greatest for those 35-64 years $(45.8 \%)$.) Denominators for rates were yearly estimates of county population by sex and age in five year groups. ${ }^{14}$ Poisson methods were used to calculate $95 \%$ confidence intervals. ${ }^{15}$ For some variables we displayed the results graphically, smoothing the rates across five year age categories using quadratic splines. ${ }^{16}$ We used Stata statistical software for all analyses. ${ }^{17}$

\section{RESULTS}

We identified 709 unintentional drownings of residents in the three counties during the 16 year period. The highest rates were among those $0-4$ years ( 31 per million), closely followed by those 15-19 years (30 per million). Lowest rates were among those $5-14$ years ( 12 per million) (fig 1 , tables 1 and 2 ).

Most drownings (78\%) involved males. Rates were highest among males $15-19$ years ( 43 per million) (fig 2 ). The male to female rate ratio was greatest among those 20-34 years (6.8, $95 \%$ confidence interval 4.6 to 10.1 ) and was closest to 1 at the extremes of age.

Most drownings (84\%) involved whites. African-Americans accounted for only $9 \%$ of drownings, but their drowning rate was more than double that of whites ( 35 compared with 17 per million). Native Americans also had high drowning rates (31 per million) compared with whites (table 2).

For all age groups, the highest rates were in the warm months (table 2).

Most drownings (72\%) were in open water. Among those 15-35 years, more than $90 \%$ of drownings occurred in open water. At the extremes of age, however, open water drownings were less common. Among children $0-4$ years, rates were nearly equally distributed between swimming pools and open water; their highest drowning rates ( 11 per million) were in swimming pools. Among those older than 65 years, most drownings $(57 \%)$ occurred in bathtubs. Bathtub drowning rates were highest ( 11 per million) among those over 65 years and those younger than 5 years.

Fifty four percent of drownings were in rural settings. At the extremes of age, most drownings occurred in urban locations ( $65 \%$ of $0-4$ years and $64 \%$ of those older than 65 years). In contrast, among those between 15 and 34 years, most drownings occurred in rural locations; $77 \%$ of those $15-19$ years and $64 \%$ of those $20-34$ years.

The majority (74\%) of those $0-4$ years fell into a body of water; almost all other children in that age group $(24 \%)$ drowned while bathing. Between the ages of 5 and 34 years, most drownings $(176 / 321,55 \%)$ were associated with either boating $(26 \%)$ or swimming (29\%). Those $15-19$ years had the highest rates for drowning while swimming, boating, or driving a car $(9,8$, and 3 per million respectively). The majority $(57 \%)$ of those over 65 years drowned while bathing. Those at 
Table 2 Rate of submersion death per million person years, with $95 \%$ confidence intervals, in three Washington State counties, 1980-95, by category of age and characteristics of the victim or event

\begin{tabular}{|c|c|c|c|c|c|c|c|}
\hline \multirow[b]{2}{*}{ Characteristic } & \multicolumn{6}{|c|}{ Age group (years) } & \multirow[b]{2}{*}{ All ages } \\
\hline & $0-4$ & $5-14$ & $15-19$ & $20-34$ & $35-64$ & $\geqslant 65$ & \\
\hline All & 31 (25 to 38 ) & $12(9$ to 15$)$ & 30 (24 to 37$)$ & 21 (19 to 24 ) & 13 (11 to 15$)$ & 21 (17 to 26$)$ & 18 (17 to 20$)$ \\
\hline \multicolumn{8}{|c|}{ 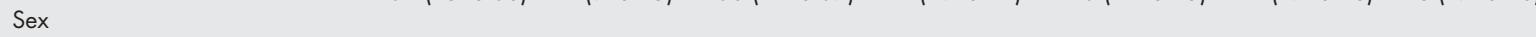 } \\
\hline Male & 42 (32 to 53 ) & 19 (14 to 25 ) & 49 (38 to 63) & 37 (32 to 43 ) & 20 (16 to 23 ) & 28 (21 to 38$)$ & 29 (27 to 31$)$ \\
\hline Female & $19(13$ to 28$)$ & 4 (2 to 7$)$ & $9(5$ to 16$)$ & 5 (4 to 8 ) & 6 (4 to 8$)$ & $16(12$ to 22$)$ & 8 (7 to 9) \\
\hline \multicolumn{8}{|l|}{ Race } \\
\hline White & 30 (23 to 37$)$ & 10 (7 to 14$)$ & 33 (25 to 42$)$ & 19 (16 to 21$)$ & $13(11$ to 15$)$ & 19 (15 to 24$)$ & 17 (16 to 19$)$ \\
\hline Black & 38 (16 to 74$)$ & 40 (21 to 69) & 36 (12 to 85$)$ & 39 (25 to 58$)$ & 29 (16 to 48 ) & $19(2$ to 70$)$ & 35 (27 to 45$)$ \\
\hline Hispanic & $0(0$ to 27$)$ & $0(0$ to 17$)$ & $11(0$ to 61$)$ & $16(6$ to 34$)$ & $4(0$ to 20$)$ & $25(1$ to 138$)$ & 8 (4 to 15$)$ \\
\hline Asian & $5(0$ to 26$)$ & 11 (3 to 27$)$ & $41(18$ to 80$)$ & $10(4$ to 21$)$ & $0(0$ to 5$)$ & 39 (14 to 85$)$ & 11 (7 to 16) \\
\hline Native American & 22 (1 to 123$)$ & 0 (0 to 46$)$ & 0 (0 to 97$)$ & 64 (29 to 122) & 30 (8 to 76$)$ & 0 (0 to 189$)$ & 31 (17 to 51$)$ \\
\hline \multicolumn{8}{|l|}{ Seasont } \\
\hline Cold & 5 (3 to 9$)$ & $2(1$ to 3$)$ & 5 (3 to 9) & 5 (4 to 7$)$ & $4(3$ to 5$)$ & $6(4$ to 9$)$ & $4(4$ to 5$)$ \\
\hline Mild & $8(5$ to 12$)$ & 3 (1 to 4 ) & 5 (3 to 9) & $6(5$ to 8$)$ & $4(3$ to 5$)$ & $6(4$ to 9$)$ & 5 (4 to 6$)$ \\
\hline Warm & 17 (13 to 23$)$ & $7(5$ to 10$)$ & 19 (14 to 25$)$ & 10 (8 to 12$)$ & $5(4$ to 7$)$ & 9 (7 to 13$)$ & $9(8$ to 10$)$ \\
\hline \multicolumn{8}{|l|}{ Event witnessed $t$} \\
\hline Yes & 3 (2 to 6) & 3 (2 to 5 ) & 17 (12 to 22$)$ & 11 (9 to 13) & $4(3$ to 5$)$ & 2 (1 to 4$)$ & $6(5$ to 7$)$ \\
\hline No & 26 (21 to 33 ) & 6 (4 to 8 ) & 5 (3 to 9) & $5(3$ to 6$)$ & $4(3$ to 5$)$ & 5 (3 to 8$)$ & $6(6$ to 7$)$ \\
\hline \multicolumn{8}{|l|}{ Body of water } \\
\hline Pool & 11 (8 to 15) & 3 (2 to 5 ) & $1(0$ to 3$)$ & $1(0$ to 2$)$ & 1 (1 to 2$)$ & 2 (1 to 4$)$ & 2 (2 to 3$)$ \\
\hline Bathtub & $9(6$ to 13$)$ & $1(0$ to 2$)$ & $1(0$ to 3$)$ & 2 (1 to 2$)$ & $2(1$ to 3$)$ & 11 (8 to 15$)$ & 3 (3 to 4$)$ \\
\hline Outside & 11 (7 to 15) & $8(6$ to 11$)$ & 28 (22 to 36$)$ & 19 (17 to 22$)$ & $10(8$ to 11$)$ & 8 (6 to 12$)$ & 13 (12 to 14$)$ \\
\hline \multicolumn{8}{|l|}{ Location } \\
\hline Rural & $10(7$ to 15$)$ & $7(5$ to 9$)$ & 22 (16 to 28 ) & 13 (11 to 16$)$ & $7(6$ to 9$)$ & $7(5$ to 11$)$ & $10(9$ to 11$)$ \\
\hline Urban & $19(15$ to 25$)$ & 4 (2 to 6$)$ & $6(4$ to 10$)$ & 7 (6 to 9) & 5 (4 to 6$)$ & 13 (10 to 17$)$ & 7 (7 to 8 ) \\
\hline \multicolumn{8}{|l|}{ Activity } \\
\hline Boating & $0(0$ to 1$)$ & 1 (1 to 3$)$ & 8 (5 to 13$)$ & 5 (4 to 7$)$ & 3 (2 to 4$)$ & $1(0$ to 3$)$ & 3 (3 to 4$)$ \\
\hline Swimming & $0(0$ to 2$)$ & 4 (2 to 6$)$ & 9 (6 to 14$)$ & 5 (3 to 6$)$ & 1 (1 to 2 ) & 1 (1 to 3$)$ & 3 (2 to 4$)$ \\
\hline In car & $0(0$ to 1$)$ & 0 (0 to 1$)$ & 4 (2 to 7$)$ & 3 (2 to 4 ) & 1 (1 to 2 ) & 0 (0 to 2$)$ & 2 (1 to 2 ) \\
\hline Fell in & 22 (17 to 28 ) & 4 (2 to 6$)$ & 5 (2 to 8$)$ & 5 (3 to 6$)$ & 3 (2 to 4$)$ & 5 (3 to 8$)$ & 5 (5 to 6$)$ \\
\hline Bathing & 8 (4 to 11$)$ & $1(0$ to 2$)$ & $1(0$ to 3$)$ & $2(1$ to 3$)$ & 2 (2 to 3$)$ & 11 (8 to 15) & 3 (3 to 4$)$ \\
\hline Was in a boat & 0 (0 to 2$)$ & 1 (1 to 3 ) & 8 (5 to 12$)$ & 7 (5 to 8$)$ & $4(3$ to 5$)$ & 3 (2 to 5$)$ & $4(4$ to 5$)$ \\
\hline Seizure history & $1(0$ to 4$)$ & 1 (1 to 3 ) & 3 (1 to 5$)$ & 2 (1 to 3$)$ & 2 (1 to 3$)$ & 1 (0 to 2$)$ & 2 (1 to 2$)$ \\
\hline Diabetes & $0(0$ to 1$)$ & $0(0$ to 1$)$ & $0(0$ to 2$)$ & $0(0$ to 1$)$ & $0(0$ to 1$)$ & $1(0$ to 3$)$ & $0(0$ to 1$)$ \\
\hline Heart disease & $1(0$ to 2$)$ & $0(0$ to 1$)$ & $0(0$ to 2$)$ & $0(0$ to 1$)$ & 3 (2 to 4$)$ & $16(12$ to 20$)$ & $3(2$ to 3$)$ \\
\hline Psychiatric disorder & $0(0$ to 1$)$ & $0(0$ to 1$)$ & $0(0$ to 1$)$ & $1(0$ to 2$)$ & $1(0$ to 2$)$ & 2 (1 to 4$)$ & $1(0$ to 1$)$ \\
\hline Alcohol used & $0(0$ to 1$)$ & $0(0$ to 1$)$ & $6(3$ to 9$)$ & $9(7$ to 11$)$ & 5 (4 to 7$)$ & $3(2$ to 5$)$ & $5(4$ to 6$)$ \\
\hline Bystander resuscitation & 22 (17 to 28$)$ & $5(3$ to 7$)$ & $6(3$ to 9$)$ & $4(3$ to 5$)$ & 3 (2 to 4$)$ & $3(2$ to 6$)$ & 5 (4 to 6$)$ \\
\hline Used pre-hospital care & $26(21$ to 33$)$ & $8(5$ to 10$)$ & $9(6$ to 13$)$ & $7(6$ to 9$)$ & $5(4$ to 6$)$ & $6(4$ to 9$)$ & 8 (7 to 9$)$ \\
\hline Used emergency department care & $23(18$ to 30$)$ & $6(4$ to 9$)$ & $6(3$ to 10$)$ & $4(3$ to 6$)$ & $2(1$ to 3$)$ & 2 (1 to 4$)$ & $5(4$ to 6$)$ \\
\hline Used hospital care & 12 (8 to 17$)$ & 3 (2 to 5$)$ & 2 (1 to 5$)$ & $2(1$ to 3$)$ & $1(1$ to 2$)$ & $2(1$ to 4$)$ & $3(2$ to 3$)$ \\
\hline
\end{tabular}

*Some data missing for most row categories. Categories with more than 10\% missing data were: event witnessed (31\%), activity (11\%), diabetes (16\%), heart disease $(15 \%)$, psychiatric disorder $(24 \%)$, bystander resuscitation $(11 \%)$.

tCold season is November, December, January, February. Mild season is March, April, September, October. Warm season is May, June, July, August.

the extremes of age had the highest rates for bathing related drownings, 11 and 8 per million in those over 65 and those $0-4$ years, respectively. Boating preceded $20 \%$ of all drownings and was the most common pre-drowning activity among those $15-64$ years.

A history of a prior seizure was present for $10 \%$ of all drowning victims and in $4 \%$ to $16 \%$ of each age group. Among those over 34 years, a history of diabetes $(8 / 200,4 \%)$, heart disease $(103 / 208,10 \%)$, and psychiatric conditions (19/160, $22 \%$ ) were sometimes found. A history of a psychiatric condition was present in only $5 \%$ of all drowning victims and most prevalent in those over age 34 years. However, most victims (84\%) older than 64 years had known heart disease.

Alcohol use was not detected in anyone younger than 15 years. Those from 20-34 and 35-64 years had the highest proportion (33\% and $35 \%$ ) of positive blood alcohol levels.

Half of all drownings were witnessed. The youngest age group was least likely to have a witnessed drowning; only $12 \%$ of drownings among those $0-4$ years were witnessed. On the other hand, most drownings in those 15-34 years were witnessed.

Only nine victims wore a life vest. All had been in small boats, most often in the early spring. Three were either pinned by or ejected into white water rapids and four submerged in $40^{\circ} \mathrm{F}$ seas or rivers where hypothermia probably contributed to their death.
Rates for any type of medical care decreased with increasing age and were lowest among those 35 years and older. Only 27\% of all victims received bystander resuscitation, but most (84\%) children $0-4$ years received bystander resuscitation. While $43 \%$ of victims and most of those $0-4$ years $(86 \%)$ and $5-14$ years $(68 \%)$ received pre-hospital care, older persons were unlikely to receive it. Only $28 \%$ were taken to an emergency department and $14 \%$ were hospitalized. However, most of those $0-4$ and $5-14$ years, $79 \%$ and $61 \%$, were taken to an emergency department and 40 and $27 \%$, respectively, were hospitalized. Older victims were more likely to be declared dead at the scene so that with increasing age, rates for any type of medical care decreased (table 2).

\section{DISCUSSION}

Within each age group general patterns of characteristics can be summarized:

- Children 0-4 years tended to fall into swimming pools or open water in urban settings while no one was around. Once retrieved from the water, they usually received bystander resuscitation, pre-hospital and emergency department care, and were usually admitted to a hospital where they died.

- Children 5-14 years had the lowest risk for drowning; they were often swimming, fell in, or were boating when the drowning occurred. 

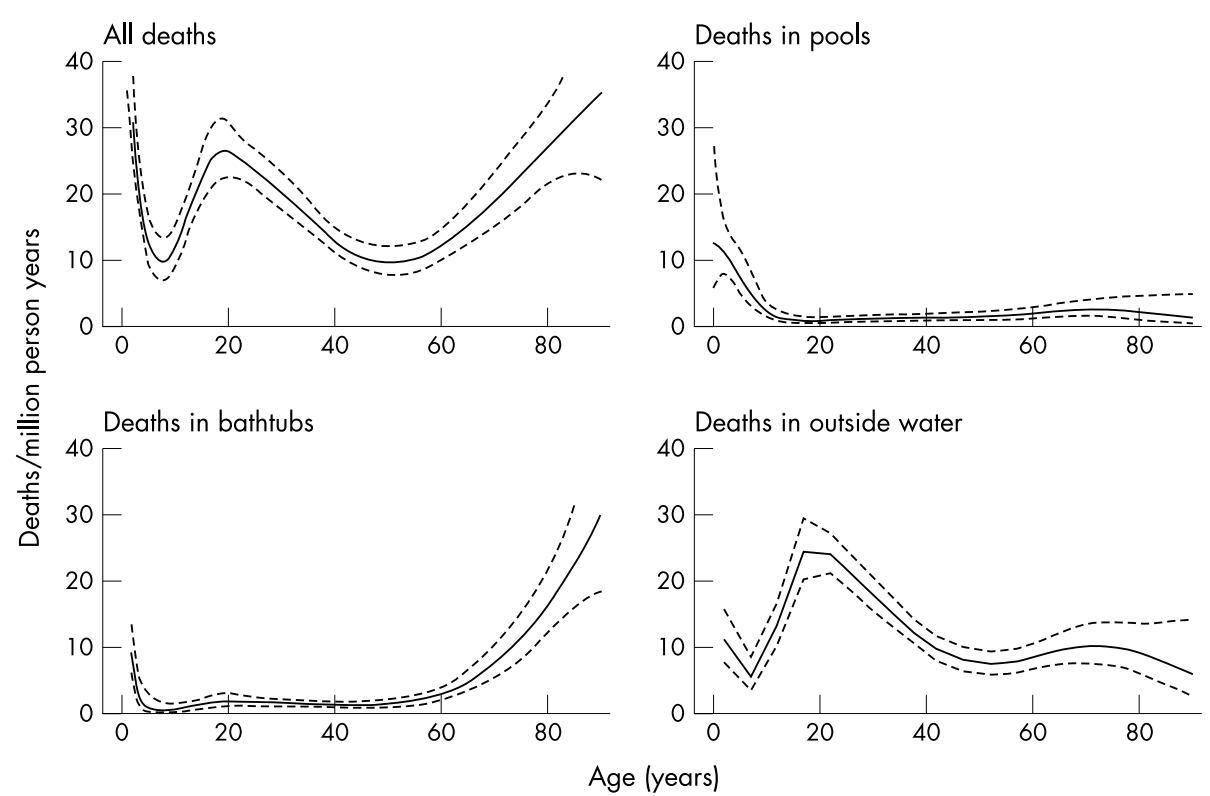

Figure 1 Age specific drowning rates, based upon data from three counties in Washington State. Solid lines show smoothed rates, bracketed by dashed lines for pointwise $95 \%$ confidence intervals.
- Adolescents aged 15-19 years had patterns similar to adults aged 20-34 years. They usually were swimming or boating in the presence of friends or others, but in a rural setting during the warm months of the year. Once retrieved, they were unlikely to receive bystander resuscitation or medical care because they were usually dead at the scene. Alcohol was a factor in 13\% and 33\% of drownings of those 15-19 and 20-34 years, respectively.
- Adults aged 35-64 years were most often boating or fell in when the drowning occurred. Alcohol use and pre-existing conditions such as heart disease and psychiatric disorders may have played a part in the event.

- Those over 64 years usually had pre-existing medical or psychiatric conditions and were most often bathing alone at home. They usually did not receive bystander resuscitation or medical care as they were often declared dead at the scene.
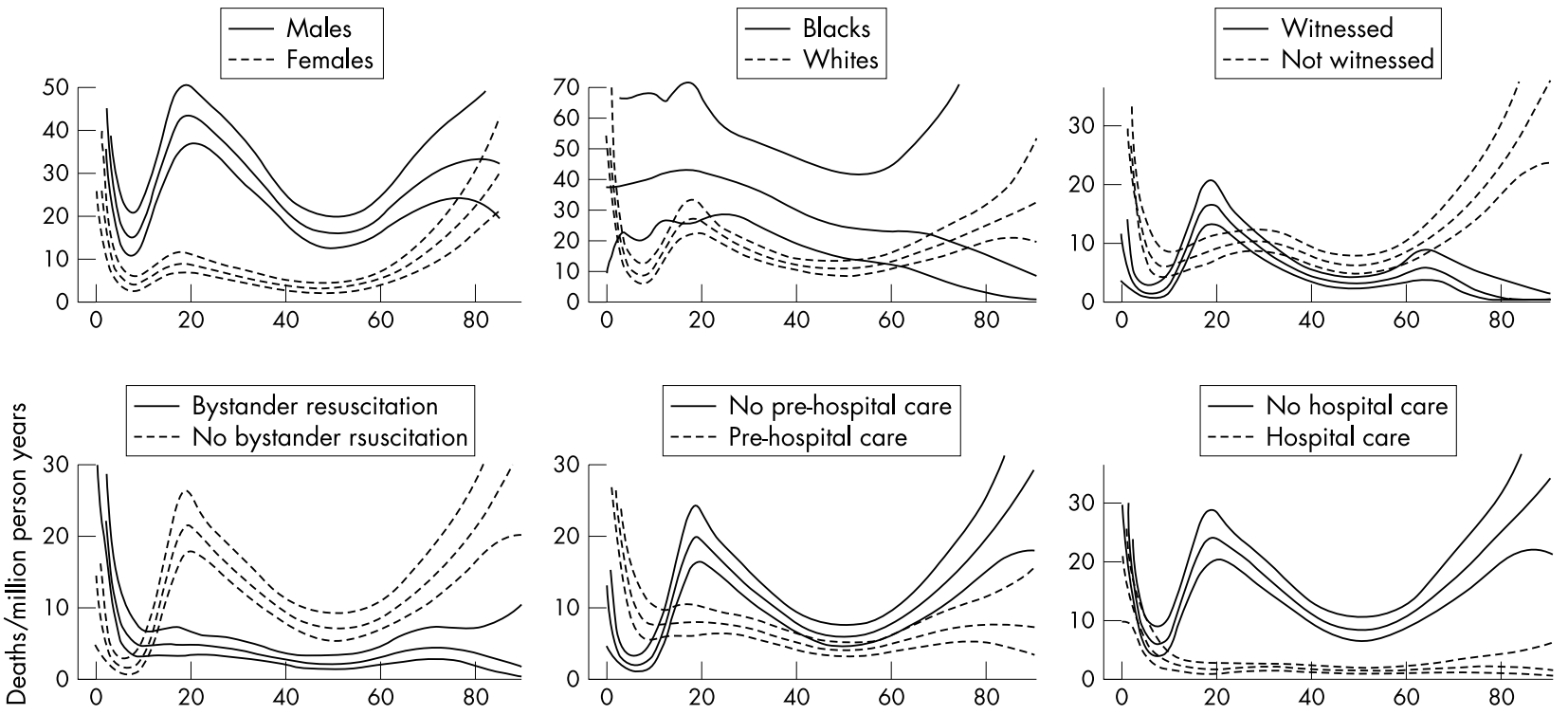

Nov, Dec, Jan, Feb
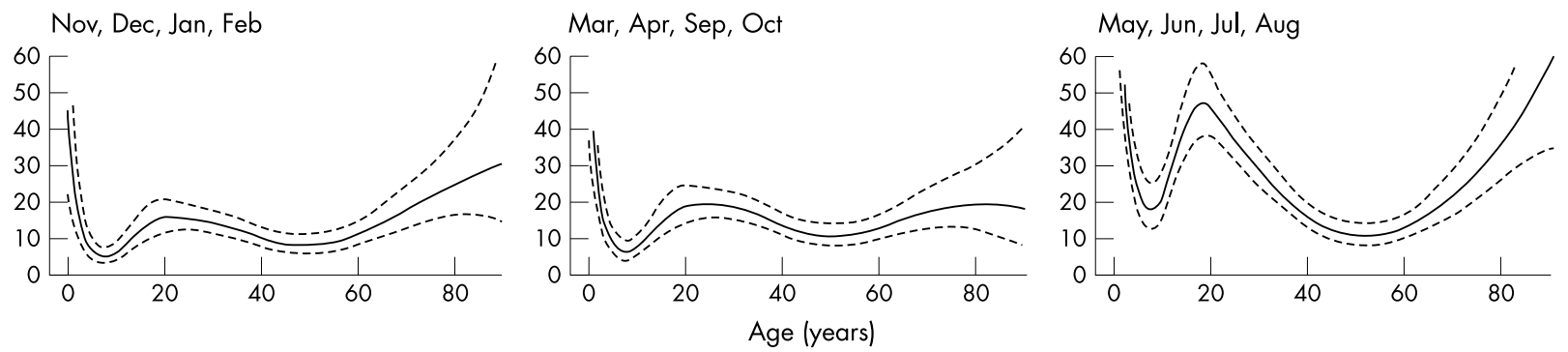

Figure 2 Age specific drowning rates, based upon data from three counties in Washington State. Smoothed plots of rates for each age group are bracketed by dashed lines for pointwise $95 \%$ confidence intervals. 
However, these characteristics do not encompass all victims within each age group. Within each age group, there was more than one scenario, each with very different mechanisms, such as those less than 5 years who drowned while bathing in the bathtub compared with those who wandered into swimming pools. Multivariate analysis of larger numbers of victims would be needed to confirm these generalizations and evaluate confounding. The potential for misclassification as to intent exists since we used medical examiners' determinations and not child abuse panels. ${ }^{18}$ Another limitation of this study is that some data were missing.

Some of these generalizations may be regionally specific. In other parts of the US most children less than 5 years fall into swimming pools since swimming pools are more common in warmer climates and drowning rates for young children are higher in most of the southwestern US. Since most adolescents and adults throughout the country and in other countries drown in open water, characteristics of these older age groups may be generalizable. ${ }^{2}{ }^{19}$ Further study is needed to identify how age related propensity to exposure to the hazard contributes to the age related characteristics. For example, the higher incidence of swimming and boating related drowning deaths among young adults may relate to their increased likelihood, relative to other ages, of engaging in these activities. Exposure data are not available for most activities.

Drowning in those over 65 years has not been well described and characteristics in this age group differed from other age groups. The prevalence of underlying disease that could contribute to the drowning was high; controlled studies are needed to determine whether these underlying diseases were over represented in these drownings. It also identifies the potential for misclassification of deaths due to drowning since a lethal arrhythmia in an older person with heart disease who is bathing will be undetected at autopsy.

A history of seizure disorder was notably present in all age groups; prevalence of a seizure history ranged from $4 \%$ among those 65 years or older to $16 \%$ among those $35-64$ years. Our finding of a high prevalence of seizures among adult drowning victims is consistent with reports from North Carolina and Canada. ${ }^{8}{ }^{20}$ Previous work suggests that children with a history of seizure have increased risk for drowning compared with the general pediatric population. ${ }^{21}$ Our data suggests that seizures may also increase the risk of drowning among adults. Of note, safety recommendations for seizure patients have been age stratified. Some have recommended that children with seizures should shower rather than bathe in a tub; given the possible continued risk with increasing age, the same recommendation should be considered for adults with a history of seizures. ${ }^{22}$ The Epilepsy Foundation of America (www.epilepsyfoundation.org/answerplace/safetyhtml) states that floatation devices are "important for children, and in some cases, adults with seizure disorder" and has no recommendations for adults with seizures and boating activities. Health care providers could convey similar recommendations to patients of all ages with seizures.

This study describes the activities involved in open water drownings by age group. In our Puget Sound region, as in national data, drowning in open water was the major site of drowning for all but those at the extremes of age. We identified the need to focus on preventing drowning while swimming and boating among those ages 5-35 years. However, the wide age span will demand targeting specific age groups. Importantly, this study shows that alcohol was a risk factor for only $28 \%$ of victims in the highest risk age group, those 15-35 years. Thus, multiple approaches, in addition to a focus on alcohol use, are needed to prevent drowning while swimming and boating.

Many recommend the use of life vests while boating. The US Coast Guard states that increased life vest use could prevent most boat related drownings (USCG boating statistics, 2000; COMDTPUB P16754.14). However, in the US, laws

\section{Key points}

- Victims' characteristics, pre-existing health conditions, activities, location of drowning, and use of medical resources vary in discernible patterns with age.

- Drowning in open water was the major site of drowning for all but those at the extremes of age.

- Greater effort should focus on increasing life vest use in boating adults since boating was a common activity in those aged $15-64$ years.

- The highest use of alcohol, $28 \%$, was in those aged 15-35 years. Thus multiple approaches, in addition to a focus on alcohol use, are needed to prevent drowning while swimming and boating in these age groups.

- A history of seizure disorder was present in all age groups (range 4\%-16\%). Given the possible continued risk with increasing age, recommendations that children with seizures should shower rather than bathe in a tub should be considered for adults with a history of seizures.

- Rates for any type of medical care after the drowning incident decreased with increasing age and were lowest among those 35 years and older.

requiring life vest use in boats do not apply to the age groups with the highest risk and documented lowest use. ${ }^{23}$ Greater effort should be focused on increasing life vest use in boating adults.

The prevention of drowning of swimmers may require new approaches. Our finding that most young adults were swimming with a buddy or witnessed when they drowned deserves further evaluation. The present recommendation to "swim with a buddy" cannot eliminate the risk of drowning while swimming (Centers for Disease Control fact sheet: http://www.cdc.gov/ncipc/factsheets/drown.htm). Of note, US Coast Guard approved inflatable floatation devices designed for swimmers are now available and deserve evaluation.

In summary, victims' characteristics, pre-existing health conditions, activities, location of drowning, and use of medical resources vary in discernible patterns with age. Different strategies may be needed for different age groups.

\section{ACKNOWLEDGEMENTS}

We are indebted to Richard Harruff, MD, John Howard, MD, and Norman Thiersch, MD, and their staff at the King, Pierce, and Snohomish county medical examiner offices for their assistance.

Supported in part by grant R49/CCR010141-03 from the Centers for Disease Control and Prevention, Atlanta, GA.

\section{Authors' affiliations}

L Quan, Department of Pediatrics, University of Washington School of Medicine, Seattle, Washington

P Cummings, Department of Epidemiology, University of Washington School of Public Health and Community Medicine and Harborview Injury Prevention and Research Center, Seattle, Washington

\section{REFERENCES}

Bierens JJ, van der Velde EA, van Berkel $M$, et al. Submersion cases in the Netherlands. Ann Emerg Med 1989:18:366-73.

2 Brenner RA Trumble AC, Smith GS, et al. Where children drown, United States, 1995. Pediatrics 2001;108:85-9.

3 Cummings P, Quan L. Trends in unintentional drowning: the role of alcohol and medical care. JAMA 1999;28:2198-202.

4 Ellis AA, Trent RB. Drowning-the leading fatal injury among California toddlers. Berkeley, CA: Division of Communicable Disease Control, 1995.

5 Lindholm P, Steensberg J. Epidemiology of unintentional drowning and near-drowning in Denmark in 1995. Inj Prev 2000;6:29-31.

6 Quan L, Gore EJ, Wentz K, et al. Ten-year study of pediatric drownings and near- drownings in King County, Washington: lessons in injury prevention. Pediatrics 1989;83:1035-40.

7 Baker SP, O'Neill B, Karpf S. The injury fact book. 2nd Ed. New York: Oxford University Press, 1992.

8 Patetta MJ, Biddinger PW. Characteristics of drowning deaths in North Carolina. Public Health Rep 1988;103:406-11 
9 Pearn J. Drowning in Australia: a national appraisal with particular reference to children. Med J Aust 1977;ii:770-1.

10 Davis S, Ledman J, Kilgore J. Drownings of children and youth in a desert state. West J Med 1985;143:196-201.

11 Pearn J, Nixon J, Wilkey I. Freshwater drowning and near-drowning accidents involving children: a five-year total population study. Med J Aust 1976;ii(25-26):942-6.

12 US Census Bureau. Age, sex, and group quarters: 1990. Available at: http://www.factfinder.census.gov (accessed 25 February 2002).

13 National Center for Health Statistics. International classification of diseases, 9th revision, clinical modification (ICD-9-CM). Washington, DC: NCHS, DHHS Publication No (PHS) 91-1260, 1991.

14 Office of Financial Management. Intercensal and postcensal estimates of county population by age and sex, 1980-2001. Available at: http://www.ofm.wa.gov (accessed 25 February 2002).

15 Long J. Regression models for categorical and limited dependent variables. Thousand Oaks, CA: Sage Publications, 1997.
16 Greenland S. Dose-response and trend analysis in epidemiology: alternatives to categorical analysis. Epidemiology 1995:6:356-65. 17 Stata Corporation. Stata statistical software: release 7.0. College Station, TX: Stata Corporation, 1999.

18 Gillenwater JM, Quan L, Feldman KW. Inflicted submersion in childhood. Arch Pediatr Adolesc Med 1996;150:298-303

19 Wintemute GJ, Kraus JF, Teret SP, et al. Drowning in childhood and adolescence: a population-based study. Am J Public Health 1987;77:830-2.

20 Ryan CA, Dowling G. Drowning deaths in people with epilepsy. Can Med Assoc J 1993; 148:781-4.

21 Diekema DS, Quan L, Holt VL. Epilepsy as a risk factor for submersion injury in children. Pediatrics 1993;91:612-6.

22 Breningstall GN. Mortality in pediatric epilepsy. Pediatr Neurol 2001;25:9-16.

23 Quan L, Bennett E, Cummings $P$, et al. Are life vests worn? A multiregional observational study of personal flotation device use in small boats. Inj Prev 1998;4:203-5.

\section{LACUNAE}

\section{Alcohol taxation and teenage drinking}

substantial rise in drinking by young people in Australia is being associated with the rise in alcoholic
drinks that taste like soft drinks and with tax changes that have made these drinks cheaper. In the year 2001-02, the number of people aged between 12 and 17 who were treated for misuse of alcohol jumped 38\% (Alcohol and Drug Information Systems data). One of the reasons for this growth is surely that there are now scores of new drinks tailored to teenage tastes, with the alcohol masked by sweet flavourings familiar to the teenage palate-particularly soft drinks and fruit flavours. These are the drinks commonly referred to as alcopops. The other big change is that these drinks have become much cheaper as the price of traditional adult alcoholic drinks has been rising. This is the result of tax changes that greatly favour these ready-to-drink spirit mixes and sales of these alcopops and other ready- to-drink cans and bottles have doubled. The lower prices and the marketing of these products has made them the drink of choice for the under 18s. The growth in youth drinking is not focused on traditional wine and beer consumption. An Australian Drug Foundation survey revealed that 70\% of girls and boys aged 12-17 drank alcohol. Asked to name the last alcoholic drink they had consumed, almost half $(46 \%)$ named a pre-mixed drink. Another 33\% nominated spirits, while only 14\% said beer, and $8 \%$ said wine (from The Age (Melbourne) February 2003; contributed by Ian Scott). 